\title{
Flashpoint and Flame Spread Analysis of Material Coconut Fiber (Cocus Nucifera) Using Chemical Treatment of Alkali $\mathrm{NaOH}$ as a Sound Absorber Material in Ship
}

\author{
Alam Baheramsyah ${ }^{1}$, Ede Mehta Wardhana ${ }^{2}$, Nasa Dityas Fariz Pradani ${ }^{3}$ \\ (Received: 05 August 2019 / Revised: 03 December 2019 / Accepted: 05 March 2021)
}

\begin{abstract}
Glass wool has a negative impact on health, which can irritate the skin and disrupt the respiratory system. Therefore, it is necessary to have an alternative sound insulation material that is eco-friendly which has capabilities comparable to glass wool, and can also be used as heat insulation on ships. These alternative ingredients are materials from natural fiber. This research made sound absorbers using coconut fiber by soaking fiber into an alkali $\mathrm{NaOH}$ solution. Materials are selected based on density, economic value, and ease in the manufacturing process. The sound absorbers are modified using coconut fiber which is given a soaking treatment of alkaline $\mathrm{NaOH}$ solution and distilled water with a percentage of $15 \%$. Soaking aims to remove lignin content and improve the mechanical properties of coconut fiber. In this research, 9 variations were made with different compositions. Tests are based on ASTM E84 to determine the flashpoint value and the safe flame spread on the ship. From the test results, it was found that coconut coir material was given a soaking treatment of alkaline $\mathrm{NaOH}$ solution with a percentage of $15 \%$ for 2 hours with a density of $0.3 \mathrm{gr} / \mathrm{cm} 3$ and thickness $30 \mathrm{~mm}$ and using a polyurethane adhesive. The time to reach the flashpoint is $\mathbf{2 0 . 4 5}$ seconds and the average temperature of flame spread is low when compared to other specimens including glass wool. The conclusion obtained is that the sound absorbers are safe when used on a ship.
\end{abstract}

Keywords-alkaline $\mathrm{NaOH}$, coconut coir, flame spread, flashpoint, sound absorbers.

\section{INTRODUCTION}

$\mathrm{S}_{\mathrm{o}}$ ound-absorbing materials take up most of the sound energy striking them and reflect only very little [1]. This property is measured by the sound absorption coefficient $(\alpha \leq 1)$, which is the ratio between the absorbed and incident sound intensity. This value is especially high in the case of open-porous materials [2]. Conventional sound absorbers are mineral wool or polystyrene foams. Due to environmental concerns, environmentally friendly, sustainable, and renewable insulation materials come more and more to the fore as "green", alternatives to these conventional absorbers [1]. Plant-based cellulosics are promising candidates in this respect. In the literature, most acoustical behavior studies have been conducted on materials consisting of cellulose microfibers [3]- [7]. The type of sound-absorbing material currently used in the industrial world is glass wool and Rockwool which are made of fiberglass. For fiberglass and other synthetic-fiber-based materials, there are growing concerns related to health and safety issues due to the potential health hazards these materials possess. The shredding of these materials can be detrimental to the health when exposed to the eyes or lungs for instance

Alam Baheramsyah is with Department of Marine Engineering, Institut Teknologi Sepuluh Nopember, Surabaya, 60111, Indonesia. Email: abaheramsyah@gmail.com

Ede Mehta Wardhana is with Department of Marine Engineering, Institut Teknologi Sepuluh Nopember, Surabaya, 60111, Indonesia Email: edewardhana123@gmail.com

Nasa Dityas Fariz Pradani is with Department of Marine Engineering, Institut Teknologi Sepuluh Nopember, Surabaya, 60111, Indonesia. Email: nasafariz@gmail.com when their fiber are inhaled since they can lay down in the lung alveoli. In addition, they can cause skin irritation [8]. This gives an opportunity for alternative materials from organic fiber to be developed as a replacement material for producing sound-absorbing panels. Thus, much research has been carried out to discovered the potential usage of new materials for sound absorption panels. Many types of research focused on the use of natural fiber due to its advantages in sense of cost, abundant and no risk in health and safety. [9], [10].

Natural fiber can be easily obtained in many tropical and available throughout the world. Today, these fiber are assessed as environmentally correct materials owing to their biodegradability and renewable characteristics. For example, natural fiber like sisal, jute, coir, oil palm fiber have all been proved to be good reinforcement in thermoset and thermoplastic matrices. One of the natural fiber that are the object of research is coconut fiber. Coconut is a plantation plant with the widest area, wider than rubber and oil palm plants, and occupies the top rank for cultivated crops after rice. Coconut occupies an area of 3.70 million ha or $26 \%$ of the 14.20 million ha of total plantation area in Indonesia. In addition to the fruit flesh, other parts of coconut also have an economic value such as shells, tree trunks, and coconut leaves, but coconut fiber (coco fiber) receives little attention. Coconut fiber has almost reached 1.7 million tons from coconut fruit production of around 5.6 million tons per year [11]. The huge potential of coconut fiber waste has not been fully utilized for production activities that have economic added value. In the absence of optimal utilization, this waste will only cause environmental problems. 
In this study, modification of sound absorbers in the form of coconut fiber (Cocos nucifera). coconut fiber were given immersion in alkaline $\mathrm{NaOH}$ solution with a percentage of $15 \%$. Chemical modification has a direct effect on the structure of the fiber and changes the chemical composition of the fiber, reducing the tendency to absorb moisture by fiber so that it will provide a better bond between fiber and matrices. This will certainly produce better composite mechanical and thermal properties. The strength and stiffness of plant fiber mainly depend on the cellulose content. Increased cellulose content is a key factor to improve fiber properties. Natural fiber have hydrophilic properties which are properties that like or are resistant to water. The effect of alkali treatment on the surface properties of cellulose natural fiber has been investigated where the optimum content of water is able to be reduced so that it can provide interfacial bonds optimally.

\section{METHOD}

\section{A. Specimens Making}

First of all coco fiber (Cocus Nucifera) must be dried with an estimated drying of approximately 2 days can be longer or faster depending on the intense heat of the sun. to make it easier to remove impurities on coconut fiber. Then cut the dried coconut fiber with a length of approximately $2 \mathrm{~cm}$ to make it easier to soak and form the specimen. Coconut coir fiber that have been dried, cleaned, and cut to a size of about $2 \mathrm{~cm}$ will be dissolved into a distillation water solution which is added to the solid alkaline $\mathrm{NaOH}$ material. In this study alkaline, $\mathrm{NaOH}$ solution was made with a percentage of $15 \%$. For the manufacture of alkaline $\mathrm{NaOH}$ solutions with a percentage of $15 \%$, it was made using the molarity formula as follows :

$$
M=\frac{\rho \times 10 \times \%}{M r}
$$

Where:

$\mathrm{M}=$ Molarity of solution ( $\mathrm{mol} / \mathrm{liter})$

$\rho=$ Density of solution $(\mathrm{g} / \mathrm{mL})$

$\%=$ Level or percentage of mass

$\mathrm{Mr}=\mathrm{The}$ relative molecular mass of the solution

After knowing the Molarity of the solution, the next step is to determine the Mol value (n) of the volume and Molarity of the solution according to the following formula

$$
n=M \cdot V
$$

Where:

$\mathrm{n} \quad=$ Mol of solution $(\mathrm{mol})$

$\mathrm{M}=$ Molarity of solution (mol/ liter atau Molar)

$\mathrm{V}=$ Volume $(\mathrm{L})$

Then proceed with the calculation of the mass of $\mathrm{NaOH}$ required by the formula as follows

$$
m=n \cdot M
$$

$$
\begin{aligned}
& \text { Where: } \\
& \begin{aligned}
\mathrm{m}=\text { Mass }(\text { gram }) \\
\mathrm{n}=\text { Mol }(\mathrm{mol}) \\
\mathrm{M}=\text { Molarity }(\mathrm{kg})
\end{aligned}
\end{aligned}
$$

In addition to using this equation, the $\mathrm{NaOH}$ mass needed to make $\mathrm{NaOH}$ solution with the desired level can be calculated using the equation below

$$
\begin{aligned}
& M=\frac{m \times 1000}{\operatorname{Mr} \times V(m l)} \\
& m=\frac{M \times M r \times V(m l)}{1000} \\
& \text { Where: } \\
& M=\text { Molarity of solution (mol/ liter) } \\
& \mathrm{m}=\text { NaOH mass needed (gram) } \\
& \mathrm{Mr}=\text { The relative molecular mass of the solute } \\
& \mathrm{V}=\text { Volume of solution in milliliter (ml) }
\end{aligned}
$$

After the $\mathrm{NaOH}$ mass is obtained, then the $\mathrm{NaOH}$ solid is dissolved in distilled water with a volume according to the calculation of the $\mathrm{NaOH}$ solution with a percentage of $15 \%$. Then the coconut fiber will be used as specimens which will be varied soaked into a mixed solution between distilled water and $\mathrm{NaOH}$ solid for 2 hours. During these 2 hour brackets, 20 minutes once the coconut fiber will be stirred and reversed so that all coconut fiber is completely submerged into the $\mathrm{NaOH}$ solution. The next step is to drain the $\mathrm{NaOH}$ solution and distillate water until the remaining coconut fiber has been soaked. Then dry the coconut fiber by drying it to the sun directly or when the night is aerated to dry, to estimate the drying time of approximately 3-5 days depending on the intensity of the sun every day.

For making the specimen itself, it is done by soaking the coconut fiber using an alkaline $\mathrm{NaOH}$ solution with a matrix in the form of polyurethane. Specimens are made to find out the flashpoint value and material flame spread, which later the most optimal specimens will be used as recommendations for making sound absorbers because they have good safety values. The coconut husk type mass is varied with the density of the mass which is $0.1 \mathrm{~g} / \mathrm{cm} 3,0.2 \mathrm{~g} / \mathrm{cm} 3$, and $0.3 \mathrm{~g} /$ $\mathrm{cm} 3$. And the thickness is also varied by $10 \mathrm{~mm}, 20 \mathrm{~mm}$, and $30 \mathrm{~mm}$. For more details, here is a list of 9 specimens that were witnessed by a list of specimen compositions.

1) Specimen 1 = Coconut coir with soaking $\mathrm{NaOH}$ (15\%) for 2 hours with a thickness of $30 \mathrm{~mm}$ and density of $0.3 \mathrm{~g} / \mathrm{cm} 3$

2) Specimen $2=$ Coconut coir with soaking $\mathrm{NaOH}$ (15\%) for 2 hours with a thickness of $20 \mathrm{~mm}$ and density of $0.3 \mathrm{~g} / \mathrm{cm} 3$

3) Specimen $3=$ Coconut coir with soaking $\mathrm{NaOH}$ (15\%) for 2 hours with a thickness of $10 \mathrm{~mm}$ and density of $0.3 \mathrm{~g} / \mathrm{cm} 3$

4) Specimen $4=$ Coconut coir with soaking $\mathrm{NaOH}$ (15\%) for 2 hours with a thickness of $30 \mathrm{~mm}$ and density of $0.2 \mathrm{~g} / \mathrm{cm} 3$ 
5) Specimen $5=$ Coconut coir with soaking $\mathrm{NaOH}$ (15\%) for 2 hours with a thickness of $20 \mathrm{~mm}$ and density of $0.2 \mathrm{~g} / \mathrm{cm} 3$

6) Specimen $6=$ Coconut coir with soaking $\mathrm{NaOH}$ $(15 \%)$ for 2 hours with a thickness of $10 \mathrm{~mm}$ and density of $0.2 \mathrm{~g} / \mathrm{cm} 3$

7) Specimen $7=$ Coconut coir with soaking $\mathrm{NaOH}$ $(15 \%)$ for 2 hours with a thickness of $30 \mathrm{~mm}$ and density of $0.1 \mathrm{~g} / \mathrm{cm} 3$

8) Specimen $8=$ Coconut coir with soaking $\mathrm{NaOH}$ (15\%) for 2 hours with a thickness of $20 \mathrm{~mm}$ and density of $0.1 \mathrm{~g} / \mathrm{cm} 3$

9) Specimen $9=$ Coconut coir with soaking $\mathrm{NaOH}$ $(15 \%)$ for 2 hours with a thickness of $10 \mathrm{~mm}$ and density of $0.1 \mathrm{~g} / \mathrm{cm} 3$

In this study, variations were made in the form of density of $0.3 \mathrm{~g} / \mathrm{cm} 3,0.2 \mathrm{~g} / \mathrm{cm} 3$, and $0.1 \mathrm{~g} / \mathrm{cm} 3$. to calculate the mass of the specimen, use the density formula. Volume is measured based on the shape of the mold that is for cylindrical molds of PVC having a diameter of $90 \mathrm{~mm}$ and for molds in the form of beams with a width of $10 \times 20 \mathrm{~cm}$. Everything is varied in height by $10 \mathrm{~mm}, 20 \mathrm{~mm}$, and $30 \mathrm{~mm}$. To calculate density, use the equation:

$$
\rho=\frac{m}{v}
$$

$$
m=\rho \times v
$$

Where:

$$
\begin{array}{ll}
\rho & =\text { density }(\mathrm{gr} / \mathrm{cm} 3) \\
\mathrm{m} & =\text { mass of specimen }(\mathrm{gr}) \\
\mathrm{V} & =\text { volume of specimen }(\mathrm{cm} 3)
\end{array}
$$

Mass that has been calculated based on Equation (1) is a total mass. After the total mass is determined then using the ratio of 3:1 (mass of coconut choir: a mass of adhesive) to find each mass.

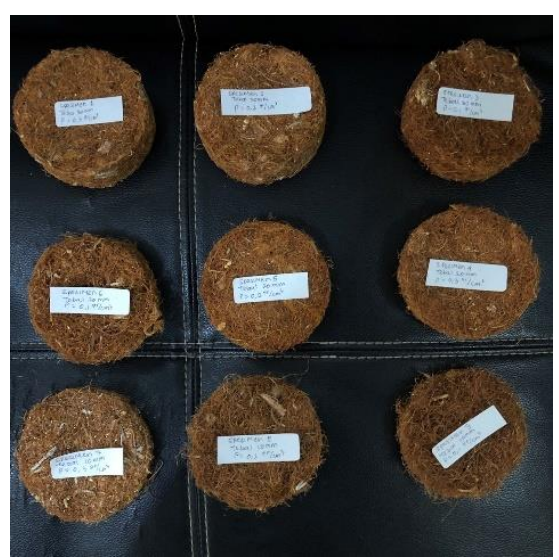

Figure. 1. Specimens with PVC mold.

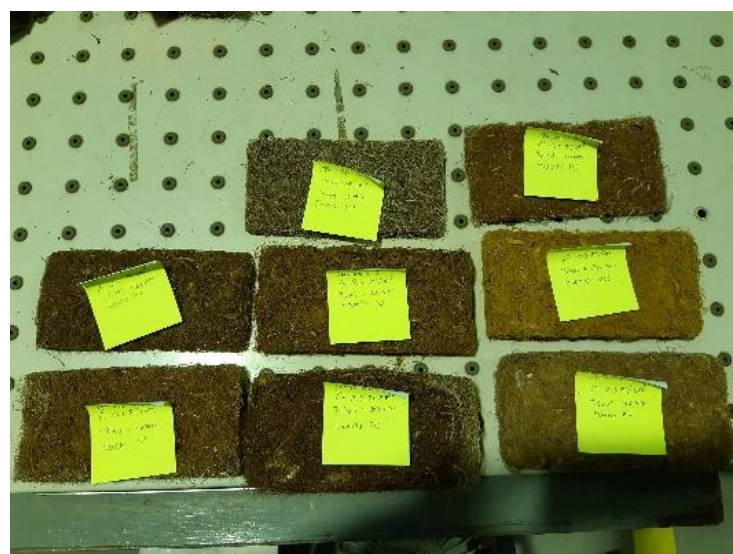

Figure. 2. Specimens with acrylic mold.

\section{B. Testing for flashpoint}

Specimens from coconut fiber will be tested for the time needed to reach the flashpoint according to the ASTM E84 standard. The test is carried out by burning the specimen with a flame torch, where the fuel source from the gas cylinder is then calculated to reach the flashpoint. In this experiment, one minute of combustion was carried out to obtain the flashpoint of each specimen. After knowing the flashpoint time obtained through the stopwatch, then look for the flashpoint temperature and the specimen using a tool such as an infrared laser thermometer.

\section{Testing for flame spread}

Coconut coir specimens will be tested for flame spread using the same tools as flashpoint testing. The tools used have been explained in the flashpoint test. By knowing the characteristics of the flame spread pattern in the specimen we can estimate how fast the material is 
burning and spreading the fire when in a room that has a source of heat with a certain distance and there are lighters. For the distance of the specimen with a lighter that is equal to $10 \mathrm{~cm}$.

\section{Data analysis}

After the experiment, the experimental data is obtained which will then be analyzed. The purpose of the analysis is to find out the shortcomings that can continue to be developed, have great benefits, and can be applied easily and safely without endangering and having a negative impact. In this research, the analysis was carried out based on the flashpoint value and flame propagation characteristics of the modified sound absorbers and glass wool sound absorbers.

\section{RESULTS AND DISCUSSION}

A. Result and discussion coconut coir is given a chemical treatment

Coconut fiber is made from lignocellulose which is a type of material that contains lignin, cellulose, and hemicellulose as its main elements. Hemicellulose and cellulose in the lignocellulose structure are covered or bound by lignin. The structure of lignin itself is very tight and strong, making it difficult for the enzymes that break down hemicellulose and cellulose to get inside. Besides lignin, another factor that can also inhibit the work of enzymes is the structure of cellulose itself.

Chemical treatment can be done in two ways, namely using a base solution or an acid solution. Between the two types of solvents, solvents that are more effective at breaking down lignin are basic solvents such as sodium hydroxide $(\mathrm{NaOH})$. In this research, the chemical treatment of coconut fiber uses an alkalization method by soaking the fiber into an alkaline solution in the form of $\mathrm{NaOH}$ solids with distilled water to remove the lignin contained in the coconut fiber. $\mathrm{NaOH}$ solution was chosen as a research material because alkaline $\mathrm{NaOH}$ is more widely used on an industrial scale which means that $\mathrm{NaOH}$ alkali is easy to find, another advantage is the price of $\mathrm{NaOH}$ solution which is relatively cheap compared to other alkaline compounds. $\mathrm{Na}^{+}$in $\mathrm{NaOH}$ solution has reactive properties and has a very small particle diameter (can enter the smallest pore of the fiber) so that it can release contaminants which in this case are lignin and oil better than other alkaline solutions.

\section{B. Mass Calculation Result}

In searching for specimen mass, density value is required, namely $0.3 \mathrm{~g} / \mathrm{cm}^{3}, 0.2 \mathrm{~g} / \mathrm{cm}^{3}$ and $0.1 \mathrm{~g} / \mathrm{cm}^{3}$. Density is the mass of a substance in each volume unit. Specimen density can be calculated by dividing specimen mass by volume of specimen shape. After getting the total mass consisting of a mixture of coconut coir mass with polyurethane adhesive mass for each specimen the next step is to find the value of each mass both coconut coir mass and polyurethane adhesive mass. In searching for the mass value, the ratio of coconut coir mass to polyurethane mass to 3: 1 is used. The value of each mass in each specimen is shown in table 1 and table 2.

TABLE 1.

MASS VALUES FOR PVC FORM

\begin{tabular}{|c|c|c|}
\hline \multirow[b]{2}{*}{ Specimen number } & \multicolumn{2}{|c|}{ Comparison of Coir Mass with Adhesive Mass (3:1) } \\
\hline & Coir mass & adhesive (Polyurethane) \\
\hline 1 & 42.959 & 9.546 \\
\hline 2 & 28.639 & 9.546 \\
\hline 3 & 14.320 & 4.773 \\
\hline 4 & 28.639 & 9.546 \\
\hline 5 & 19.093 & 6.364 \\
\hline 6 & 9.546 & 3.182 \\
\hline 7 & 14.320 & 4.773 \\
\hline 8 & 9.546 & 3.182 \\
\hline 9 & 4.773 & 1.591 \\
\hline
\end{tabular}

TABLE 2.

MASS VALUES FOR AKRILIC FORM

Specimen number $\quad$ Comparison of Coir Mass with Adhesive Mass (3:1)

Coir mass adhesive (Polyurethane)

\begin{tabular}{lll}
\hline 1 & 135.000 & 30.000 \\
2 & 90.000 & 30.000 \\
3 & 45.000 & 15.000 \\
4 & 90.000 & 30.000
\end{tabular}




\begin{tabular}{lrr}
5 & 60.000 & 20.000 \\
6 & 30.000 & 10.000 \\
7 & 45.000 & 15.000 \\
8 & 30.000 & 10.000 \\
9 & 15.000 & 5.000 \\
\hline
\end{tabular}

C. Analysis result

1) Flashpoint

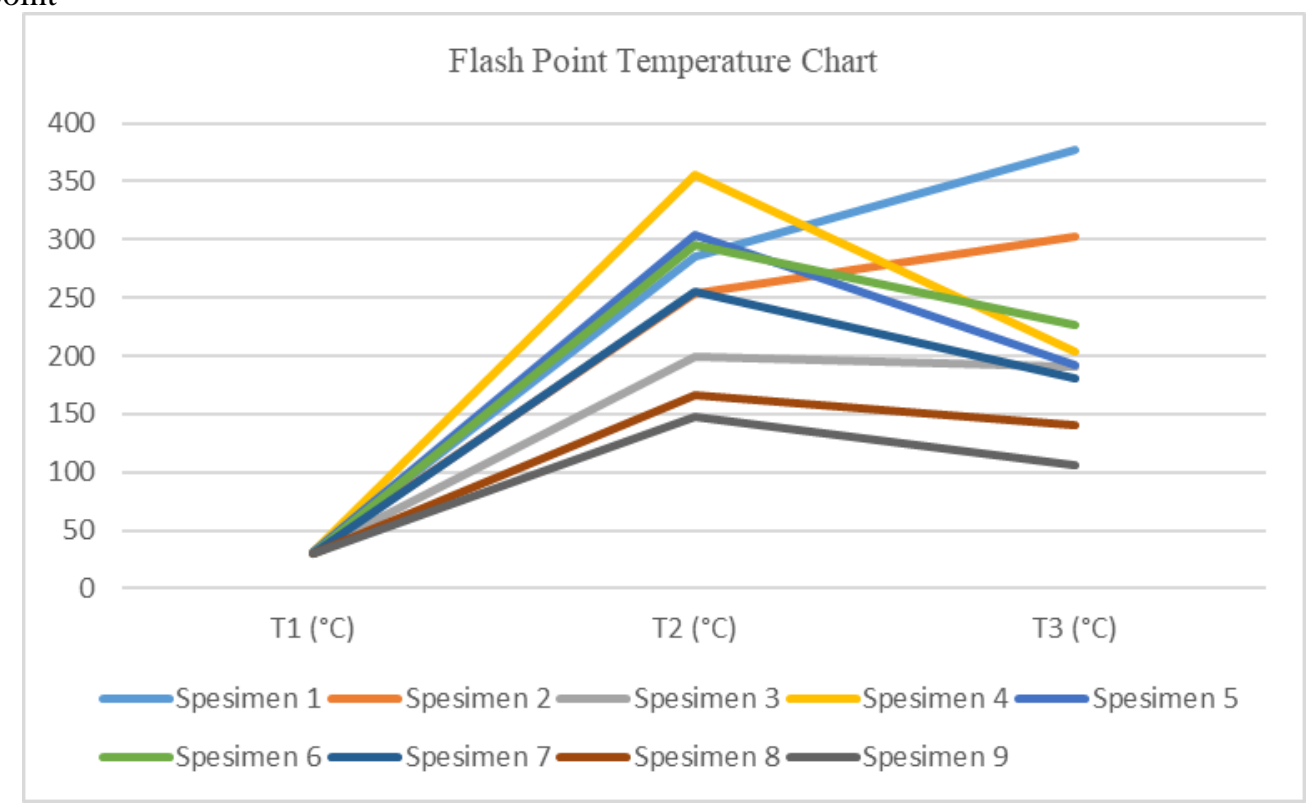

Figure. 3. Flashpoint temperatures graph.

Based on figure 3 , specimen 3 with a thickness of $30 \mathrm{~mm}$ and a density of $0.2 \mathrm{gr} / \mathrm{cm}^{3}$ has the highest flashpoint value compared to other specimens with temperatures reaching $356^{\circ} \mathrm{C}$. then followed by specimens 4 and 5 which have a high fire value with the same density of $0.2 \mathrm{gr} / \mathrm{cm}^{3}$ with specimens of $20 \mathrm{~mm}$ and $10 \mathrm{~mm}$ thick. Whereas specimen 9 with a thickness of 10 $\mathrm{mm}$ and a density of $0.1 \mathrm{gr} / \mathrm{cm}^{3}$ has the lowest flashpoint value among the other specimens with a temperature of $147^{\circ} \mathrm{C}$. The flashpoint is the lowest temperature at which a mixture of compounds with air at normal pressure can ignite after initiation, in this test it is by sparks from a flame torch. A high flashpoint value affects the safety level of the specimen because the specimen which has a high flashpoint will burn at high temperatures which later when used as a damper will be safer if the specimen has a high flashpoint.

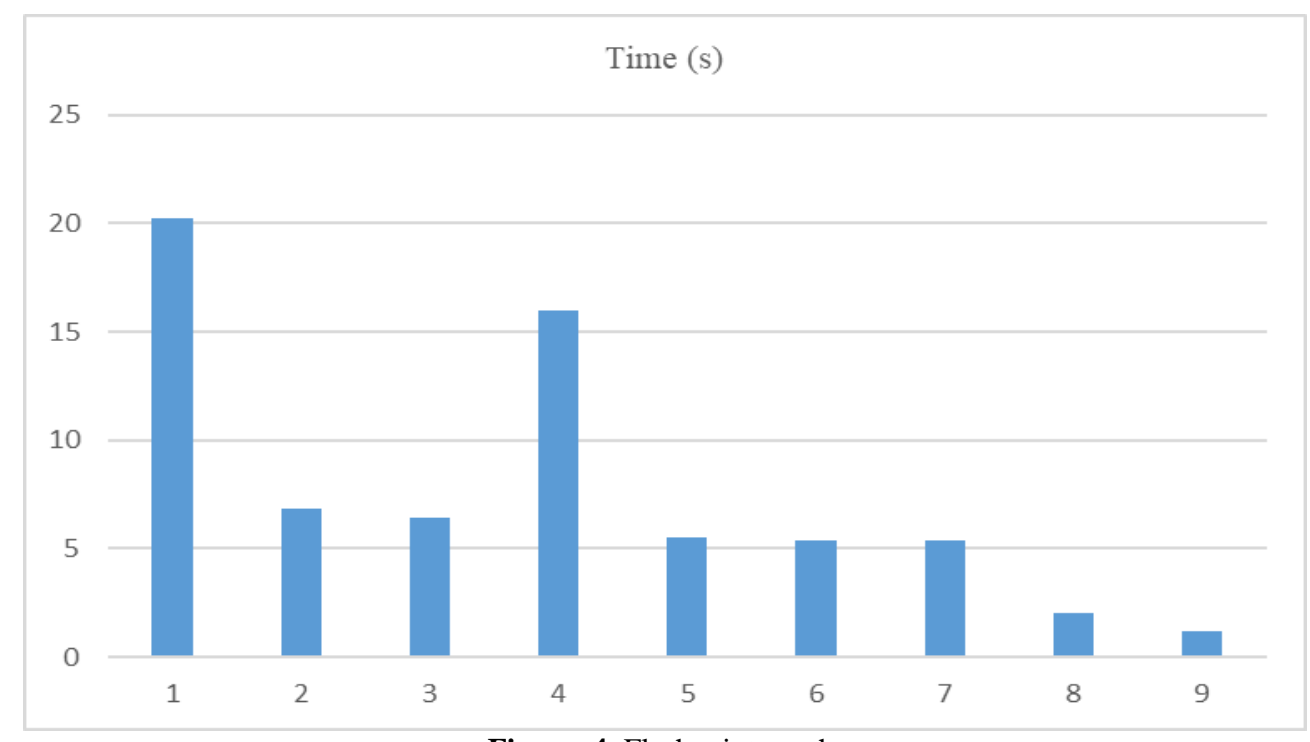

Figure. 4. Flashpoint graph. 
According to figure 4. of the experimental specimen flashpoint results shown in graph 4.2, specimen 1 was coconut husk which had been immersed in $15 \%$ alkaline $\mathrm{NaOH}$ for 2 hours with a density of 0.3 $\mathrm{gr} / \mathrm{cm}^{3}$, the specimen height was $3 \mathrm{~cm}$, and the mass composition of coir coconut and polyurethane at 42.9589 gr and 14.3196 gr have the time to be able to cause a flame at a maximum of 20.25 seconds. And for the fastest flame time is specimen 9 with a density of 0.1 $\mathrm{gr} / \mathrm{cm}^{3}$, the specimen height is $1 \mathrm{~cm}$, and has a mass composition between coconut fiber and polyurethane of $4,773 \mathrm{gr}$ and 1.591 gr. In this study, it can be seen that the greater the density and thickness of the material, the longer it takes the material for the flame to occur in the material. In addition, the mass of large polyurethane causes the material to have a longer time compared to materials that have a polyurethane composition which is a bit due to the nature of polyurethane which can make the material resistant to heat.

\section{Flame Spread}

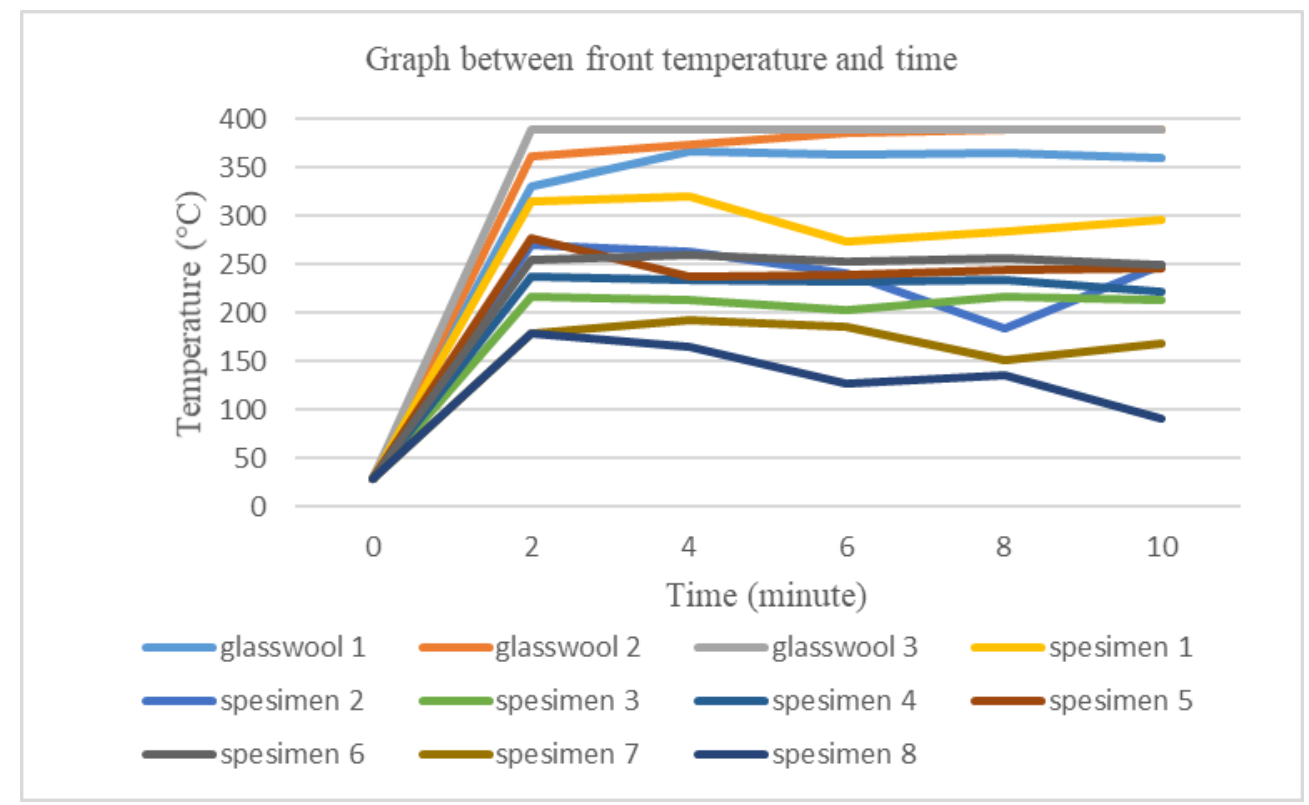

Figure. 5. The graph between the front temperature of glass wool and specimens with time.

Based on Figure 5. it is known that the temperature of the glass wool surface which comes in direct contact with the heat source has a higher temperature than the temperature of the coconut coir which has been given a $\mathrm{NaOH}$ alkaline soaking treatment of $15 \%$. The test was carried out in the MMS laboratory workshop of the Department of Marine Engineering at night so that the initial temperatures of all variations of $28.4^{\circ} \mathrm{C}$ were obtained. The graph above shows that glass wool can absorb heat higher than coconut fiber which has been given $\mathrm{NaOH}$ alkali treatment. Due to the constituent material of glass wool itself which is a mixture of natural sand with recycled glass that is heated to a temperature of $1450^{\circ} \mathrm{C}$ to form fiberglass, this fiberglass makes glass wool absorb more heat. When compared with natural fiberglass wool for higher absorption temperature because glass wool 3 can reach a temperature value of
388 0C and then followed by glass wool 2 and 1 . Coconut coir specimens that have been given an alkaline soaking $\mathrm{NaOH}$ treatment have heat absorption to direct contact with heat sources the highest is specimen 1 with a density of $0.3 \mathrm{gr} / \mathrm{cm}^{3}$ and a thickness of $30 \mathrm{~mm}$ has an average temperature value reaching $297.6^{\circ} \mathrm{C}$.

Based on Figure 5. it is known that glass wool 3 with a thickness of $10 \mathrm{~mm}$ has the hottest surface temperature when getting direct fire contact on the surface of the glass wool that is with an average temperature of $388^{\circ} \mathrm{C}$. For coconut coir which has been given $\mathrm{NaOH}$ alkaline immersion treatment is specimen 1 with a density of $0.3 \mathrm{gr} / \mathrm{cm}^{3}$ and a thickness of $30 \mathrm{~mm}$ has the highest temperature compared to specimens from other coconut coir that is with an average of $297.6^{\circ} \mathrm{C}$. 


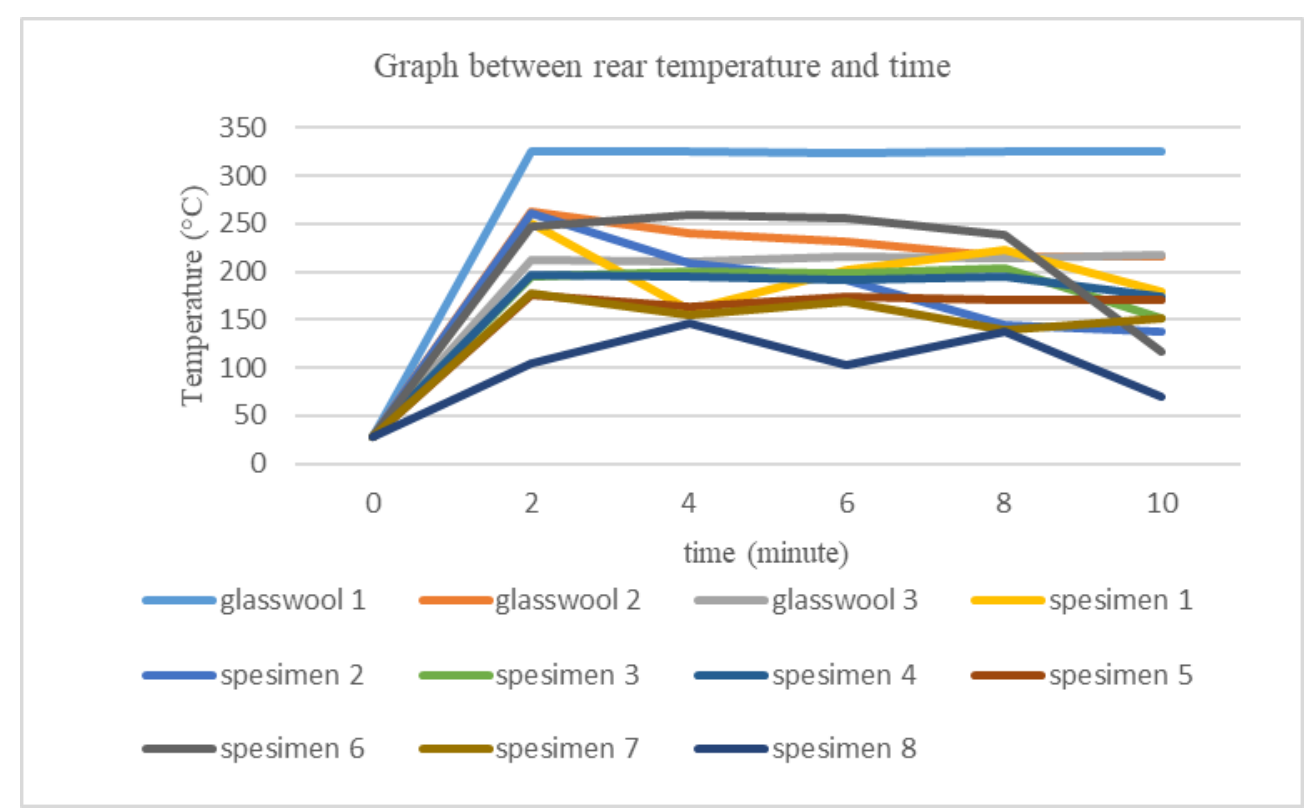

Figure. 6. The graph between the front temperature of glass wool and specimens with time.

Based on figure 6 , it can be seen that glass wool 1 with a thickness of $30 \mathrm{~mm}$ has the highest temperature when compared to variations of glass wool and other specimens that are with an average temperature of $325.2^{\circ} \mathrm{C}$. based on the graph above, the temperature of the back of glass wool 1 tends to look constant. This is because glass wool 1 does not burn out during combustion testing which causes the temperature to rise constantly and will reach the equilibrium temperature point. Glass wool 2 with a thickness of $20 \mathrm{~mm}$ when tested against the back temperature of glass wool 2, glass wool 2 also did not burn out. This is because the particle density and moisture from glass wool are better than coconut coir specimens that have been soaked in alkaline
$\mathrm{NaOH}$ because the density of the particles results in the difficulty of the mass of the glass wool evaporating coupled with less moisture compared to coconut coir making glass wool will be more difficult to burn out.

Based on figure 6 , it is known that glass wool 1 with a thickness of $30 \mathrm{~mm}$ has a high temperature that is equal to $325.2^{\circ} \mathrm{C}$ and tends to be constant during burning for 10 minutes. this is because glass wool 1 can not burn completely during combustion testing within 10 minutes. For coconut coir which has been given $\mathrm{NaOH}$ soaking treatment is specimen 1 with a density of $0.3 \mathrm{gr} / \mathrm{cm}^{3}$ and a thickness of $30 \mathrm{~mm}$ has a high temperature.

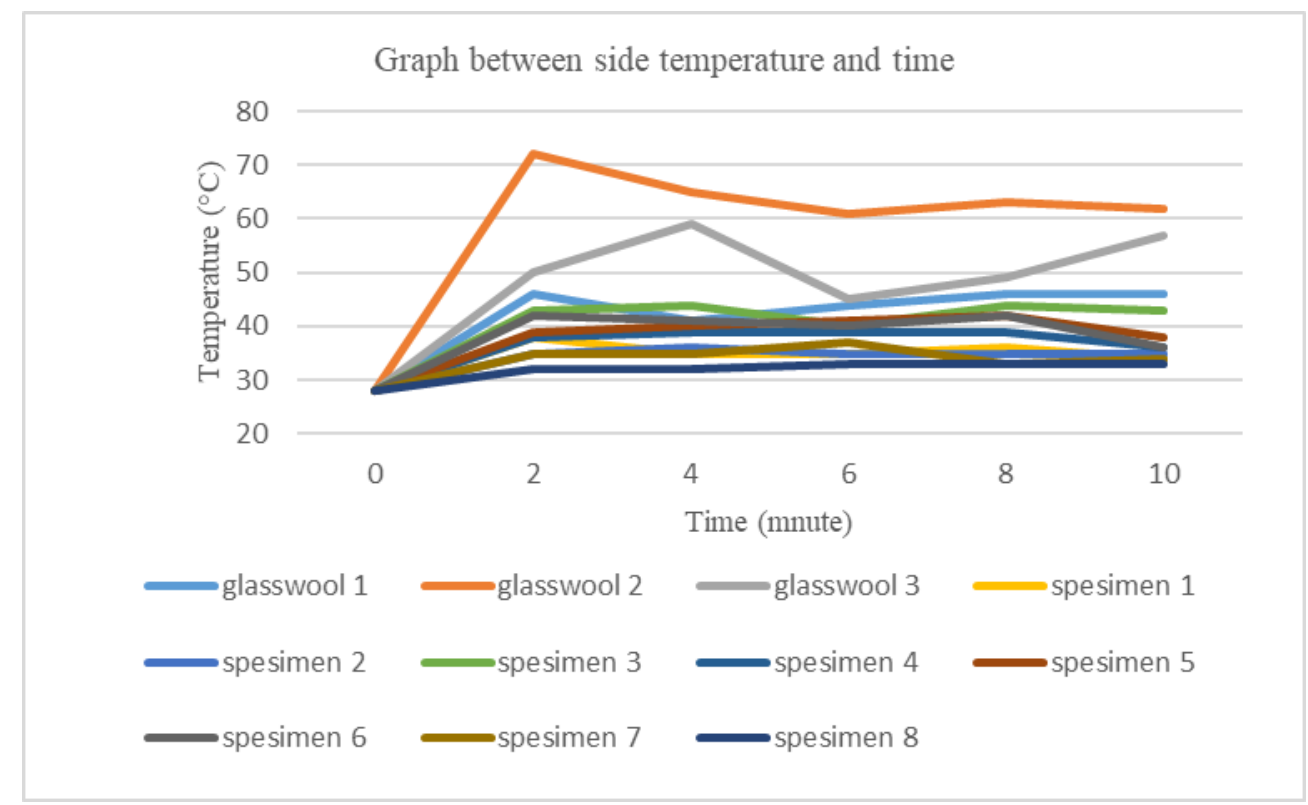

Figure. 7. The graph between the back temperature of glass wool and specimens with time.

Based on Figure 7. it can be seen that specimen 8 with a density of $0.1 \mathrm{gr} / \mathrm{cm}^{3}$ thickness of $20 \mathrm{~mm}$ has a low-temperature value compared to glass wool variations and other specimens with an average temperature of $32.6^{\circ} \mathrm{C}$. Based on these data it can be concluded that specimen 8 is not easy to conduct heat when compared with other test variations. This is due to the adhesive 
properties of the polyurethane glue which is fire retardant and also difficult to conduct heat.

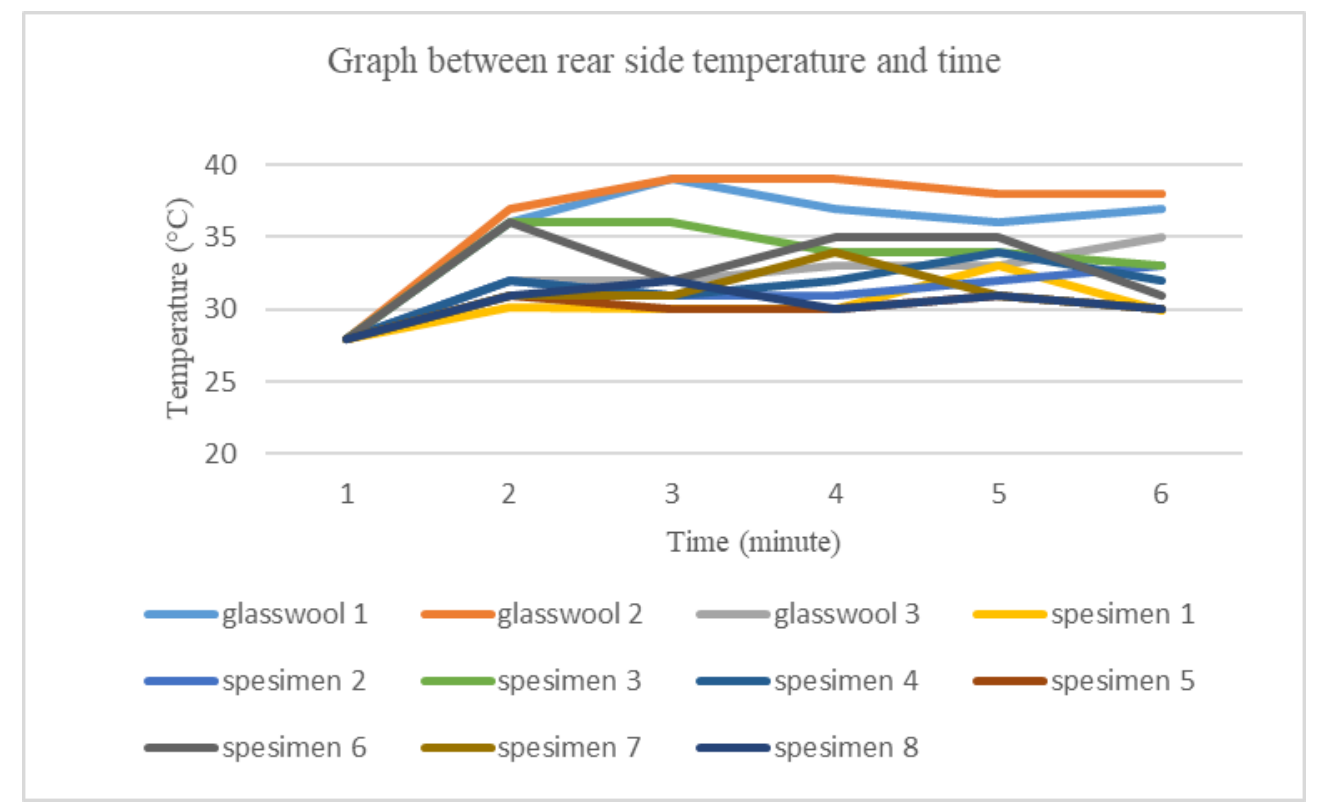

Figure. 8. The graph between the rear side temperature of glass wool and specimens with time.

Based on figure 8 it can be seen that specimen 1 with a density of $0.3 \mathrm{gr} / \mathrm{cm}^{3}$ thickness of $30 \mathrm{~mm}$ has the lowest temperature value when compared to variations of glass wool and other specimens namely with an average temperature of $30.62^{\circ} \mathrm{C}$. Based on these data it can be concluded that specimen 1 is not easy to conduct heat compared to other test variations the same as specimen 8 . This is due to the adhesive properties of polyurethane glue which is fire resistant and also difficult to conduct heat. The relationship between density and temperature which is inversely proportional is also one reason specimen 1 has a small temperature value. In this experiment, it was found that specimens from coconut coir that had been treated with $\mathrm{NaOH}$ soaking were more difficult to conduct heat when compared to glass wool. From figure 8 it can be seen that the lowest temperature in a sequence related to the propagation temperature is specimen 1 .

\section{CONCLUSION}

1) Specimen 1 in the form of coconut coir which has been given an immersion treatment of alkaline $\mathrm{NaOH}$ with a concentration of $15 \%$ glued using polyurethane with a density of $0.3 \mathrm{gr} / \mathrm{cm}^{3}$ and a thickness of $30 \mathrm{~mm}$ having the ignition time to reach the flashpoint for the longest compared to other specimens which are equal to 20.25 seconds. The temperature to reach the flashpoint is $286^{\circ} \mathrm{C}$. from the experiments that have been carried out the flashpoint is determined by the thickness and density of the material, the greater the density of the material and the thicker the material will cause the length of time for the material to arrive at the point of ignition. As for the addition of density and thickness, there are still other factors that affect the ignition time of flashpoints such as material type, ambient temperature, pressure, and so on.
2) From the results of tests that have been carried out that coconut coir which has been treated with $\mathrm{NaOH}$ soaking with a percentage of $15 \%$ using polyurethane adhesives is more difficult to propagate heat. Specimen 1 with a density of $0.3 \mathrm{gr} / \mathrm{cm}^{3}$ and a thickness of $30 \mathrm{~mm}$ has an average temperature for the sides that is lower than the others that are $31.1^{\circ} \mathrm{C}$, so specimen 1 is the specimen that is the most difficult to propagate compared to other specimens.

3) In testing coconut coir with $\mathrm{NaOH}$ soaking alkali with a percentage of $15 \%$ has a lower heat absorption temperature compared to glass wool. Based on the results of the soundproofing test with glass wool material has a hotter temperature value on the side that comes in direct contact with the source of fire compared to specimens made from coconut fiber. However, coconut coir specimens have lower heat propagation temperatures than glass wool. So that specimens based on coconut fiber are more difficult to conduct heat when compared to glass wool.

\section{REFERENCES}

[1] Arenas, J. P., \& Crocker, M. J. (2010). Recent trends in porous sound-absorbing materials. Sound \& vibration, 44(7), 12-18.

[2] A. J. Crocker MJ, Use of sound-absorbing material, 2008.

[3] Zulkifli, R., Nor, M. M., Tahir, M. M., Ismail, A. R., \& Nuawi, M. Z. (2008). Acoustic properties of multi-layer coir fiber sound absorption panel. Journal of Applied Sciences, 8(20), 3709-3714.

[4] Putra, A., Abdullah, Y., Efendy, H., Farid, W. M., Ayob, M. R., \& Py, M. S. (2013). Utilizing sugarcane wasted fiber as a sustainable acoustic absorber. Procedia Engineering, 53, 632-638.

[5] Yeon, J. O., Kim, K. W., Yang, K. S., Kim, J. M., \& Kim, M. J. (2014). Physical properties of cellulose sound absorbers produced using recycled paper. Construction and Building Materials, 70, 494-500.

[6] Pöhler, T., Jetsu, P., \& Isomoisio, H. (2016). Benchmarking new wood fiber-based sound-absorbing material made with a foamforming technique. Building Acoustics, 23(3-4), 131-143.

[7] Nechita, P., \& Năstac, S. (2018). Foam-formed cellulose composite materials with potential applications in sound insulation. Journal of composite materials, 52(6), 747-754. 
[8] Asdrubali, F. (2006, May). Survey on the acoustical properties of new sustainable materials for noise control. In Proceedings of Euronoise (Vol. 30, pp. 1-10). Tampere: European Acoustics Association.

[9] Yang, H. S., Kim, D. J., \& Kim, H. J. (2003). Rice straw-wood particle composite for sound absorbing wooden construction materials. Bioresource Technology, 86(2), 117-121.

[10] Paul, W., Jan, I., \& Ignaas, V. (2003). Natural fiber: can they replace glass in fiber-reinforced plastics. Compos Sci Technol, 63(9), 1259-1264.

[11] Budisuari, "2-3," 2007. [Online]. Available: www.halamansatu.net. [Accessed 12 October 2012].

[12] A. Baheramsyah, E. M. Wardhana, and M. A. Husein, "Analysis of Palm Fiber and Coconut Coir Usage as Purse Seine Cargo Chamber Insulator," Int. J. Mar. Eng. Innov. Res., vol. 3, no. 1, pp. $18-26,2018$.

[13] L. N. Sawdust, R. S. Insulation, A. Baheramsyah, E. M. Wardhana, and P. L. Sihombing, "Coolbox design for traditional fishing vessel using sengon wood (paraserianthes falcataria (1.) Nielsen) sawdust and rice straw insulation," Int. J. Mar. Eng. Innov. Res., vol. 3, no. 2, 2018.
[14] M. Abidin, A. Baheramsyah, and E. M. Wardhana, "Cooling System Design for Cold Storage of Traditional Fishing Boat Using Insulation from Rice Husk," Int. J. Mar. Eng. Innov. Res., vol. 3, no. 1, pp. 34-39, 2018.

[15] A. Baheramsyah, E. M. Wardhana, and A. T. R. Kisserah, "Utilization of Mixture of Teak Wood Sawdust and Bagasse Fiber using Treatment of Fiber Variations and Alkali $\mathrm{NaOH}$ Immersion as A Refrigerator Insulation Material,” Int. J. Mar. Eng. Innov. Res., vol. 4, no. 2, pp. 122-130, 2019.

[16] T. F. Nugroho, W. Busse, E. M. Wardhana, and J. I. O Panggabean, "Heat Transfer Analysis of Thermal Oil Plant on Fuel Oil Tanks of 17500 LTDW Product Oil Tanker,” Int. J. Mar. Eng. Innov. Res., vol. 2, no. 2, 2018. 